\title{
THE CONDESCENDING AND MISOGYNISTIC PORTRAYAL OF WOMEN IN MEDIA
}

\author{
Bordoloi A* and Srimathi SP \\ Indian Institute of Psychology and Research, India
}

\begin{abstract}
The sexual objectification of women in media, and their portrayal, strictly adhering to gender roles is rampant, even in today's day and age. This needs to be investigated and deliberated upon, to shed light on how patriarchal notions dominate society, until this date. The way, in which women have been represented across media platforms, ranging from movie posters, movies to even television advertisements, has an immense impact on the viewer, even if it may be a negative one.

Feminist Research Methodology will be used with an experiential and analytical study of secondary sources of information such as movies and magazines. This methodology is used, to explain phenomena from the perspective of the woman, thus emphasizing the experiential analysis method. The research is grounded on feminist values and beliefs and addresses the problems of gender inequality and sexual objectification of women. The paper would examine the topic on the condescending and misogynistic portrayal of women in the media.
\end{abstract}

The hypothesis would be that the effects of the portrayal of women through a misogynistic and condescending lens in the media could impact and influence the perception and beliefs of the viewer and consumers. The research aims to understand how Patriarchy still has a massive influence on the sexual objectification and oppression of women through concepts such as the male gaze. The problems of colorism, wooing of women in Bollywood, targeted advertisements that reinforce gender roles and the portrayal of women in pornography will be explored.

The outcome of the research would be an increased awareness as to how viewers and consumers of media internalize gender roles and mindlessly propagate such ideals of sexually objectifying women's bodies and other similar concepts such as social comparison and the effect on women's self-esteem due to narrow beauty standards. The research would also be helpful in guiding creators and influencers to represent both the sexes equally with the same respect and dignity.

Keywords: misogynistic, portrayal, media, colourism, patriarchy, gender, sexual objectification

\section{Introduction}

Laura Muvley (1975), in her essay, "Visual Pleasure and Narrative Cinema" came up with the concept of Male-Gaze. Through a psychoanalytic viewpoint, she used the scopophilic instinct which refers to looking at another person as an erotic object, to explain the characteristic nature of cinema, which sexually objectifies women's bodies, only to cater to heterosexual male desires. This concept, which originated in the $1970 \mathrm{~s}$, still has immense relevance in the $21^{\text {st }}$ century. After the notorious 2012 Delhi 
Gang rape and murder case, a few Indian news channels directly blamed "item songs" that were blatantly used in Bollywood movies, as responsible for influencing rape, as an outlet of male sexual desires, and power over women. The portrayal of eve-teasing and the relentless pursuit of a lady, until she succumbs to the charms of a man, in cinema is rampant even now. Very recently, the lyrics of a song called, "Beyonce Sharma Jaayegi”, faced much backlash after it was shamed for invoking racism and colourism.

The endorsements of fairness creams by celebrities is a deep-rooted problem, which only contributes to the preference of fair-skinned individuals, thus adding to the dangerous problem of colourism. These instances force us to yearn for a society that celebrates gender equality and a refusal to conform to toxic standards and norms of what "beauty" entails. Racism is already a problem that is plaguing the planet. Colourism makes this problem even worse, when we subject the citizens of our very own country, to oppression, if they do not follow standards of beauty, set by so-called "first-world" countries.

Added to the problem of setting toxic beauty standards for women, as can be witnessed in matrimonial advertisements in Indian newspapers, (the demand for tall, fair, and beautiful brides), is the evil of sexual objectification, which will be discussed by exploring topics further. Gender roles are so deeply ingrained in our society that the traits assigned to women, such as tenderness and submissiveness are taken for granted, as women solely become targets of commercial advertisements, responsible for marketing products for doing household chores (laundry detergents, toilet cleaners, surface disinfectants). On the other hand, initiatives by banks such as home loans, are targeted towards men, reinforcing their roles as the sole breadwinners of the family.

\section{Review of Literature}

Tere N. S (2005) conducted a study to investigate on gender reflections in mainstream Hindi cinema. The paper deals with representations of women characters in mainstream Bollywood movies. It is deemed appropriate to examine this issue because women are a major chunk of the country's population and hence their portrayal on screen is crucial in determining the furtherance of already existing stereotypes in society. The paper begins with a discussion on the field of feminist film criticism and how mainstream Hindi Cinema has restricted itself to defined sketches of womanhood. It also undertakes some glimpses from popular films to analyze this process of stereotyping the "other" - considering that reality in mainstream cinema is constructed from the male viewpoint. A section is devoted to discussion on the contemporary realistic brand of cinema and its understanding of women. In conclusion, a debate ensues on whether mainstream Hindi cinema has been successful in portraying Indian women of different shades in a society dominated by patriarchal values. The study concluded that cinema's only end is not to entertain. It must begin a quest for social change through entertainment. As a media product, identified to accelerate the process of modernity, cinema should not stick to the "formula film". It should come up with more progressive representations of women. Such portrayals would do justice to women and their role in society.

Patowary H., (2014), conducted a study on the Portrayal of Women in Indian Mass Media. The analytical method of research design was used along with secondary sources of data to analyse the feminist understanding of media and the media's role in constructing the images of women. The study concluded that the overall effect of the portrayal of women in media is to reinforce rather than reduce 
prejudices and stereotypes. The study also concludes that Indian mass media has not made adequate efforts to discuss serious issues concerning women and prepare women for playing their equal role in society. To change this situation, it is of the urgent requirement to carefully monitor the media, and continuously point out their merits and demerits.

Mishra, Deepanjali. (2015), conducted a study to examine the portrayal of women in media. The paper emphasizes on how the portrayal of women in media, be it in advertisements or soaps, can be sexist, and adhere to gender roles. For example, women in advertisements are predominantly portrayed as homemakers who tend to the needs of the children and husbands, while in soaps, they are portrayed as authoritative within the domestic sphere. It also talks about how movies and television reinforce the importance of a thin body as a measure of a woman's worth. Research studies are indicated wherein the exposure of thin female bodies and the crafted bodies of models, is linked to depression, loss of self-esteem and the development of eating disorders. The importance given to fair skin is also mentioned, the reason for which being the Western/racist ideals of beauty. The conclusion that can be drawn from all these findings is that the usual way of portraying women in media, which is inherently sexist, consists of an undercurrent, whereby a message is being portrayed to the audience, which only serves to reinforce socio-cultural stereotypes.

Greenfield, S. (2018), conducted a study on, "When beauty is beast: The Effects of Beauty Propaganda on Female Consumers." The paper focuses on the impact of advertisements, which shape the action of female consumers and evaluates women's motivation in continuing to buy beauty products. A link between negative effects and consumer motivations is discussed to highlight the sexism that is rampant in beauty industries. The hypothesis of the study is threefold and is that the imagery used by the beauty industry has negative effects on female consumers by providing unrealistic standards and lowering self-esteem, these effects create a strong need to purchase beauty products to fit the ideals of modern society and just as advertising previously shifted with social movements, the \#metoo and \#TimesUp campaigns could potentially change the portrayal of women. The study concludes that advertisements portray an over-sexualised and unattainable ideal of beauty which leads to negative views of one's body image, negative moods, self-esteem, health, consumption patterns, health and much more. These advertisements create a void in women which can only be filled by buying beauty products, which would then lead them to their desired beauty ideals. However, because of the unattainable nature of the beauty ideal, there is a constant demand for beauty products. The growth of feminism and intolerance towards sexual harassment which can be witnessed with the \#metoo and \#TimesUp movements, and further social unrest may create sufficient social pressure to bring about a change in the industry.

Sibal,V. (2018) conducted a study on the representations of women characters in mainstream Bollywood movies. Women constitute fifty percent of the population and hence their portrayal on screen is crucial in determining the stereotypes that exist in society. The paper begins with a discussion on the field of feminist film criticism and how mainstream Hindi cinema has restricted itself to defined sketches of womanhood. It also undertakes some glimpses from popular films to analyse this process of stereotyping. Cinema is always constructed from the male viewpoint. In conclusion, a debate ensues on whether mainstream Hindi cinema has been successful in portraying Indian women of different shades in a society dominated by patriarchal values. The paper concluded that it is time that cinema seeks a redefinition of women as objects of the male gaze and that proper 
and fair narration of women's experiences, without the use of stereotypes, can help for the imperative cause of women's equality.

Slatewala Z. Z (2019) conducted a study to investigate the objectification of women in Bollywood item numbers. The study reflected on the ways of objectification of women in India by analysing Bollywood rap and item songs. Based on objectification theory, one of the primary goals in the study was to measure differences between visual and behavioural sexual objectification, drawing on theoretically derived indicators of sexual objectification. It also concentrated on measuring the change in the objectification patterns over the years. This was done by conducting a content analysis of 201 songs $(n=201)$. The findings suggested that the visual objectification of women was higher than the behavioural objectification of women and that there is a shift in the common themes and the level of objectification over the decades. The study also concluded that problematic representations of women in Bollywood songs deserve further research attention because they likely affect other attitudes and self-perceptions as well, including attitudes toward sexuality, conceptions and understandings of masculinity and femininity, and women's rights.

\section{Research Methodology}

\section{Aim}

The paper would examine and investigate the condescending and misogynistic portrayal of women in media.

\section{Hypothesis}

The effects of the portrayal of women through a misogynistic and condescending lens in the media could impact and influence the perception and beliefs of the viewer and consumers.

\section{Objectives}

To critically analyse how Patriarchy still has a massive influence on the sexual objectification and oppression of women through concepts such as the male gaze. The problems of colourism, wooing of women in Bollywood, targeted advertisements that reinforce gender-roles and the portrayal of women in pornography will be explored.

\section{Research Design}

The experiential analytical method will be used whereby secondary sources of information will be utilised to critically analyse the subject material. The topic will further be examined by taking a deeper look into the direct experiences of the researcher in relation to the topic. The research design will constitute Feminist Research Methodology since it is from the standpoint perspective of a woman, addresses gender inequality and sexual objectification of women and is grounded on feminist beliefs and values. 


\section{Research Questions}

The research questions used in the study will pertain to whether the portrayal of women in media is misogynistic and condescending. Such portrayals will be studied to understand how they affect consumers of related media; such as on self-esteem.

\section{Data Collection}

Secondary sources of information will be used for data collection, which includes movies, advertisements, books and magazines.

\section{A closer look at Patriarchy, Beauty and Femininity, Bollywood and Pornography}

\section{Patriarchy}

According to Britannica, Patriarchy can be defined as a "hypothetical social system in which the father or a male elder has absolute authority over the family group; by extension, one or more men (as in a council) exert absolute authority over the community as a whole." In today's day and age, the effects of this so-called "male-dominance", presents itself to us, in the malicious maladies of genderinequality as expressed in sexual violence and harassment against women, domestic violence, gender wage-gap and many such atrocities. Starting from the first Women's Rights Convention in 1848 at Seneca Falls, all the way through the different waves of Feminism such as the radical notions of feminist thinkers such as Shulamith Firestone until the recent trends on Twitter such as the \#metoo movement, the world has come a long way, in understanding how Patriarchy with its oppressive roots, plays a major role in social interactions and behaviours. However, it indeed affects how women are portrayed in media.

Starting from the internalization of gender roles at a very young age, such as girls identifying with the colour pink and boys identifying with the colour blue, or the common phrase, "stop crying like a girl", we learn to assume certain social responsibilities and adhere to social norms from a very young age. This is sadly reinforced by the media. Advertisements in television, such as those for washing liquids and detergents, (Pril, Vim, Surf Excel) reinforce the gender roles of women being subjugated to the household and being in charge of chores such as cleaning and cooking. These advertisements are aimed at women, and blatantly categorize household chores as something that concerns only women.

\section{Beauty Products and Femininity}

Colourism can be defined as discrimination against people with a different skin tone, especially within the same racial group. This is heavily perpetuated by the global beauty industry where sales of skinlightening products are projected to reach 8.9 billion dollars by 2024. Colourism is also very prevalent in countries with white minorities due to the aftermath and influence of colonialism. This sadly has a huge role to play when it comes to education, employment and media representation. In India, beautypageant organizers are criticized for preferring and selecting only those contestants who meet Eurocentric beauty standards, and in African countries, Governments struggle to regulate the sale of dangerous skin-lightening products. 
For example, a study (Harrison M., Thomas K., 2009) examined the influence of colourism on job selection and discovered a significant preferential difference among Black applicants based on their skin complexion. The findings suggest that skin tone plays a considerable role in the favourability of a Black applicant; indicating that skin colour is more salient and regarded more highly than one's educational background and prior work experience.

(Mishra, N. 2015) conducted a study to investigate the phenomenon of colourism in India. The conclusion was that even average well-educated urban Indian females have skin colour in mind while undergoing day-to-day functions, let alone the ones with lesser exposure or education or belonging from rural areas which still holds the majority of the Indian population. It is easier for such women to get influenced even faster and end up spending part of their earning in buying fairness products under media influence wanting to transform their lives.

The shocking part of the matter is that celebrities, who are supposed to be our so-called, "role models", endorse skin-lightening products, which only contribute to fair skin being considered supreme when it comes to good beauty standards. The fairness-cream market, especially in SouthAsian countries, is a booming industry and it is indeed in the marketing process where the importance given to fair skin, supersedes human values, causing darker-skinned individuals, to suffer lower levels of self-esteem because their skin tone is not desirable enough. This can be observed in fairness-cream commercials, where once, light skin is attained after the use of bleaching and skin-whitening products, everything falls into place and it is easier to attract somebody from the opposite sex. The Fair and Lovely beauty cream, is a brutal example, staring us right in the face when it comes to the comparison between skin tones. Even though, the name has been changed to "glow and lovely", the ideals of fair skin and the harmful bleaching materials, still haven't changed. This shows that the media, decides, what "beauty standards" constitute and relays the information to its consumers, thus propagating lower levels of self-esteem among those who do not meet them.

A campaign to strongly fight against colourism, called DARK IS BEAUTIFUL, has made considerable efforts in spreading awareness on the impact of colourism. On January 18, 2014, the Dark Is Beautiful team delivered a petition of 30.000 signatures to a cosmetic company called Emami, reasoning with them and persuading them to withdraw a particularly discriminatory advertisement for Fair and Handsome. In June 2014, Dark is Beautiful lobbied against advertisements that discriminate against dark skin and called for the Advertising Council of India (ASCI) to legislate guidelines that would stop advertisements of fairness products. This prompted ASCI to come up with new guidelines for advertisements.

\section{Bollywood Movies and Women's Sexuality}

In 2015, an Indian man in Australia was taken to court because he stalked and harassed two women. His lawyer argued that the man was influenced by Bollywood movies that portrayed harassment or stalking to be considered as normal when it came to seeking romantic relationships with women. The man, Sandesh Baliga, who was a security guard claimed that Bollywood had taught him that the relentless pursuit of a woman, was the only way to woo them. In the end, the court magistrate had agreed that his cultural background had affected him, and let him go freely on the condition that he would promise to show good behaviour for the next five years. This shocking incident relays the 
direct influence of media, on behaviour, be it good or bad. After all, when will women be portrayed, as having minds and decisions of their own?

In Salman Khan's movie, Dabangg 2 (2012), actress Kareena Kapoor danced in an "item number", or rather a song with a blatant portrayal of a woman as per the highest standards of male-gaze; the lyrics to which are,

"Main toh tandoori murgi hoon yaar,

Gatkale saiya alcohol se",

which can be translated to, "I am just a tandoori chicken in a tandoor, just swallow me, dear lover, with alcohol". This is only a small example of how women are being portrayed, as nothing more than sex objects for male gratification.

Although, movies such as "Lipstick Under My Burkha", talk about women's experiences through a fair and just narration, most Bollywood movies, still lack the common sense, to vouch for women's emancipation. The age-old narrative of women being under the control of men, which adheres to patriarchal norms still has not changed. Even though during the infamous 2012 Delhi Gang-rape incident, news channels had explicitly mentioned the role of Bollywood movies, especially of "item numbers" in encouraging men, to freely and powerfully exert their dominance and need for sexual gratification over women and thus leading to an increasing number of sexual assault cases, Bollywood seems to merrily carry on with their misogynistic traditions. TV serials, do not fall far behind when it comes to the unjust portrayal of women in media.

\section{The need to "tame" women}

The plot of the movie, Bhabhi (1991), revolves around an incident where a woman (Sita) had slapped a man, who was trying to make sexual advances towards her. Later on, when the man, was seeking to marry and was going through pictures of eligible women for an arranged marriage, he saw her picture and decided to marry her, only to make the rest of her life miserable, as revenge for her hitting him. The woman, (as confusing as it may sound), finally understood that her husband was the same man, whom she had once hit. The storyline from this moment on focuses on the aim of the husband and her in-laws in making life miserable for her, even with an attempt to kill her. The sad part, however, is that Sita, continues to respect her husband, throughout the entire movie, and even forgives him towards the end. Movies such as this, showcase how, women need to cling to their roles of being loving, patient and considerate despite what their husbands and in-laws put them through.

Another observation is that generally, when a movie focuses on the male protagonists(s), cheating on their wives, the genre is usually a comedy. However, when it focuses on infidelity from the woman's side, the genre changes to intense drama. Examples of such cases are movies such as No Entry, Thank you, Biwi No. 1 or Shadi No. 1, Kabhi Alvida Na Kehna and Hamari Adhuri Kahani. In the movie, No Entry, Salman Khan's character cheats on his wife for several years, but she (Esha Deol), decides to forgive him because he threatened her with suicide. 
The plight of misogyny does not seem to find its end. One of the most shocking dialogues to be used in any movie, is in the movie, Grand Masti (2013), where one of the characters exclaim,

"Balatkar se yaad aaya,

\section{Meri Biwi Kahan hai?"}

which can be literally translated to, "After hearing the word rape, I just remembered, where is my wife?". Sexual assault or scenes encouraging it, is blatantly being showcased in films like Judwaa 2 (2017), where two twins, have an inherent inclination to spank women, randomly in public. However, the women do not create a scene whatsoever and treat the entire situation as normal. In the movie, Rajaa Ki Aayegi Baaraat (1997), the lead actress gets raped and when this case is taken to court, the verdict was that the man who had raped her, should marry her and give her an honourable place in the family. To think about it, these scenes should have caused an upheaval, but were rather ignored and forgotten. Wife-beating has been portrayed in movies such as Aamdani Atthanni Kharcha Rupaiya (2001), where it is considered absolutely normal to physically assault women. The protagonist in the movie, has firm beliefs about where women stand in society and threatens to beat his wife if she ever crosses her boundaries or disrespects his wishes.

It is important to include homosexual relationships in the conversation of the portrayal of women in media. Lesbian relationships have not been encouraged in movies such as Fire (1996), where several protests took place after the movie was released. The movie, Un-freedom (2015), was banned in India, due to its explicit sexual content displaying a homosexual, lesbian relationship. The portrayal of homosexual relationships in Bollywood, is still deemed to be too problematic even at this point of time. This goes to show how uncomfortable the audience gets, when women's sexuality is openly displayed, and how it is completely normal for men to exert their dominance on women, only to satisfy their "men's needs."

\section{Pornography and Sexual Violence against Women}

To talk about how pornography relates to the misogynistic and condescending portrayal of women in media, I would like to highlight the important conclusions of emeritus professor, Robert Jensen's TedX talk on "RADICAL FEMINISM IS A GIFT TO MEN" (2019).

He starts by talking about the time when he was introduced to radical feminists living in a patriarchal society who critiqued men's sexual exploitation of women in the pornography industry. He affirms that "masculinity in patriarchy is relentlessly competitive, focused on conquest, which leads to inevitable confrontations, all with the quest of staying in control of oneself, and controlling others." The end-product of this masculinity, which strongly correlates to gender roles, is that men do not feel "man enough", and as a consequence may seek to control and own women's bodies through the sexual exploitation industries such as pornography. Men can buy and sell objectified female bodies for sexual pleasure.

His most radical argument is that, "can you imagine creating or maintaining a stable, decent society with gender-justice when one class of people (women, girls), can be routinely bought and sold for the sexual pleasure of another class of people (men)?" He believes that pornography is without a doubt, the most sexist and racist media genre in the world today. He states that when men's sexuality is tied 
to the use of objectified female bodies in pornography, and a sense of control of women, they lose out on the possibility of a deeper and more meaningful sense of intimacy. The realistic conclusion that can be drawn, is that, "Our relationships can deepen if we escape pornographic imaginations." Sir Robert Jensen's speech, indicates how the media, is a well-accustomed and intrinsic part, of a cycle that reinforces patriarchal norms, gender roles and the sexual objectification of women.

\section{Discussion and Conclusion}

Institutionalised male dominance is omnipresent. Male-gaze is observed in almost all media platforms, like for example, the image of a beautiful semi-naked woman bathing in a waterfall to advertise soap. Certain small villages in parts of rural India, Haryana (North-India), for example, still firmly believe that when young girls wear jeans, it motivates men to rape them. It is indeed ironic how so many people across the globe gleefully consume media content that sexually objectifies women's bodies, but at the same time make absolutely no efforts to stop sexual or any other forms of violence against women. It is high time that we were more sensitive and sensible as to how individuals are being portrayed in media, as it definitely helps consumers form opinions and views after consuming content. Gender is a spectrum, and it would make no sense, not to include individuals from the LGBTQ+ community, when we believe that individuals of all genders should be represented equally, and with dignity and respect.

Patriarchy is ever-present in the media even today. The study confirms the hypothesis which states that the effects of the portrayal of women through a misogynistic and condescending lens in the media could impact and influence the perception and beliefs of the viewers and consumers. The stalking and harassment case registered in 2015, against an Indian security guard in Australia, is a clear indicator of how the effects of the portrayal of women in media, has devastating real-life consequences. However, concepts such as the male-gaze, are not the only major problems that are plaguing the media. Colourism, or the measure of one's worth, solely based on the colour of their skin, is blatantly being reinforced when skin-whitening products benefit from celebrity endorsements. This is directly reflected when matrimonial advertisements in India, clearly seek, "fair and beautiful" brides. As a consequence of imperialism and colonization, our ideals of beauty are influenced by the West, as we glorify those who meet Eurocentric standards of beauty. Women should be portrayed as independent individuals, who are capable of making decisions for themselves, rather than being made targets of advertisements of dish-washing liquids, laundry detergents or toilet cleaners (household cleaning products), thereby reinforcing gender-roles. This paper aspires to encourage all individuals, especially women, to boldly voice their opinions on how the media carries on being a slave and a medium to patriarchal norms. Women are not merely sex objects and submissive beings and deserve decent and respectable representation across all media platforms. A limitation to analysing secondary sources of information for this paper, is that there is hardly any information on how a plethora of organisations have come forward to reject the practices of media to reinforce toxic beauty standards and misogynistic trends. This could have helped, bring forth a stronger notion for change. Hopefully in the future, due to the work of scholars and activists, can media content creators be more mindful about how they deal with appropriate gender representation in media. This can help viewers in being mindful of and combating issues such as low self-esteem, after the heavy use of fake and filtered media This is the $21^{\text {st }}$ century, and it is time that we get rid of the old ways of portraying women on 
screen, and focus more on their accomplishments and independence rather than on their sexual objectification.

\section{References}

Loreck, J (2016) Explainer: What does the 'male-gaze' mean, and what about a female gaze? Retrieved from https://theconversation.com/explainer-what-does-the-male-gaze-mean-and-whatabout-a-female-gaze-52486

Patowary, Himashree. (2014). Portrayal of Women in Indian Mass Media: An Investigation.https://www.researchgate.net/publication/333036807_Portrayal_of_Women_in_Indian_ Mass Media An Investigation

Mishra, Deepanjali. (2015). PORTRAYAL OF WOMEN IN MEDIA. Journal of Higher Education and

Research

Volumehttps://www.researchgate.net/publication/284431132 PORTRAYAL OF WOMEN IN ME

DIA/citation/download

Greenfield, Savannah, "When Beauty is the Beast: The Effects of Beauty Propaganda on Female

Consumers" (2018). Theses/ Capstones/Creative Projects. 20.

https://digitalcommons.unomaha.edu/university honors program/20

Sibal, Vatika. (2018). STEREOTYPING WOMEN IN INDIAN CINEMA. Scholarly Research Journal for Interdisciplinary Studies. $5 . \quad 10.21922 /$ srjis.v5i43.11253. https://www.researchgate.net/publication/323786469_STEREOTYPING_WOMEN_IN_INDIAN_CI NEMA

Harrison, M., Thomas K, M (2009) The Hidden Prejudice In Selection : A Research Investigation on skin-colour bias. https://onlinelibrary.wiley.com/doi/abs/10.1111/j.1559-1816.2008.00433.x

Mishra, Deepanjali. (2015). PORTRAYAL OF WOMEN IN MEDIA. Journal of Higher Education and Research. Volume 3. https://www.researchgate.net/publication/284431132_PORTRAYAL_OF_WOMEN_IN_MEDIA/cita tion/download

Slatewala, Zahabia Z. (2019), "Objectification of Women in Bollywood Item Numbers" . Graduate Theses and Dissertations. https://scholarcommons.usf.edu/cgi/viewcontent.cgi?article=9145\&context=etd

Tere, N.S (2005), "Gender Reflections in Mainstream Hindi Cinema" Global Media Journal - Indian Edition/ISSN 2249-5835 Sponsored by the University of Calcutta/ www.caluniv.ac.in Summer Issue / June 2012 Vol. 3/No.1. Retrieved from https://www.caluniv.ac.in/global-mdiajournal/Students\%27\%20Research/SR4\%20NIDHI.pdf

Advocacy Initiatives: Dark is Beautiful. Retrieved from https://www.darkisbeautiful.in/advocacy/

Lakshmi, R (2015), A man in Australia accused of stalking women blamed it on women. His case was dismissed. https://www.washingtonpost.com/news/worldviews/wp/2015/02/02/a-man-in-australiaaccused-of-stalking-women-blamed-it-on-bollywood-his-case-was-dismissed/

Jensen, R. (2019), Radical Feminism is a gift to men, TedXRuhrUniversityBochum. Retrieved from https://youtu.be/Mi5TG3E4rnE

5 absolutely bizarre Indian movie scenes that will leave you speechless. Tried and Refused Productions (2021). Retrieved from https://youtu.be/rBBvZ1ZlHKU

5 Regressive and Shocking Indian movie moments that everyone ignored. Tried and Refused Productions, (2018). Retrieved from https://youtu.be/9VLxhDqcofk 